\title{
Impact toughness of an S700MC-type steel: Tempforming vs ausforming
}

\author{
A. Dolzhenko ${ }^{\mathrm{a}}$, Z. Yanushkevich ${ }^{\mathrm{a}, *}$, S.A. Nikulin ${ }^{\mathrm{b}}$, A. Belyakov ${ }^{\mathrm{a}}$, R. Kaibyshev ${ }^{\mathrm{a}}$ \\ a Belgorod State University, Pobeda 85, Belgorod 308015, Russia \\ b National Science and Technology University "MISIS", Moscow 119049, Russia
}

\section{A R T I C L E I N F O}

\section{Keywords:}

High-strength low-carbon steel

Ausforming

Tempforming

Ultrafine grained microstructure

Delamination toughening

\begin{abstract}
A B S T R A C T
The effect of different thermomechanical treatments, i.e., ausforming and tempforming, on the microstructure and mechanical properties including impact fracture behavior of high-strength low-carbon S700MC-type steel was investigated. The tempforming resulted in the development of ultrafine grained elongated grain microstructure with the transverse grain size of $530 \mathrm{~nm}$, whereas the ausforming led to the formation of typical tempered martensite structure with a distance between high-angle boundaries of $1.5 \mu \mathrm{m}$. The tempered microstructures involved the formation of carbides with an average particle size about $50 \mathrm{~nm}$ and $\mathrm{M}(\mathrm{C}, \mathrm{N})$-type carbonitrides with average size of $10 \mathrm{~nm}$. The tempformed steel exhibited the ultimate tensile strength of $1110 \mathrm{MPa}$ and the impact toughness, KCV, above $450 \mathrm{~J} / \mathrm{cm}^{2}$ at a temperature of $293 \mathrm{~K}$, and $\mathrm{KCV}$ of $109 \mathrm{~J} / \mathrm{cm}^{2}$ at liquid nitrogen temperature for impact direction perpendicular to rolling plane. In contrast, KCV of the ausformed steel was 180 and $10 \mathrm{~J} / \mathrm{cm}^{2}$ at 293 and $77 \mathrm{~K}$, respectively. The enhancement of toughness was associated with delamination cracks which occurred in the ultrafine elongated grain structure with anisotropic properties.
\end{abstract}

\section{Introduction}

High-strength low-alloy (HSLA) steels are widely used materials due to their low cost and good combinations of strength, ductility and toughness [1-3]. However, this type of steels with high strength typically exhibits low Charpy V-notch impact energy of 10-40 J at lowered temperatures [1-3]. Such low toughness often limits their structural applications. Structural steels have to be both strong and tough. These steels could not be used at temperatures below the ductile-brittle transition temperature (DBTT), at which the steel loses its toughness and fracture occurs in a brittle mode. The grain refinement is one of the most promising approaches to decrease DBTT concurrently with strengthening of structural steels and alloys [4-7]. The ultrafine grained structure decreases the stress concentration at grain boundaries, especially at triple junctions [7].

The water-cooled thermo-mechanical processes are widely used to obtain high strength and superior toughness in HSLA steels through grain refinement [5]. The direct water spray quenching after controlled rolling results in martensite structures in HSLA steels. The lath martensite consists of prior austenite grains, packet, blocks and laths with high dislocation densities [3,8-10]. The use of thermo-mechanical process with direct quenching (ausforming) allows remarkable refinement of the martensite structural elements [5]. Other effective methods for grain refinement involve cold rolling of martensite followed by annealing or warm rolling of tempered martensite $[10,11]$. However, the strengthening by refining the grain size to $1 \mu \mathrm{m}$ or less tends to degrade the tensile ductility and toughness [8]. An interesting approach to increase the toughness and decrease DBTT of HSLA steels was proposed by Kimura et al. [12]. This method consists of the formation of a lamellar structure with the transverse grain size of about $100 \mathrm{~nm}$ and a uniform distribution of dispersed nanosized particles of secondary phases in steels owing to specific thermo-mechanical processing, i.e., tempforming, which allows obtaining a promising combination of mechanical properties in low-alloyed steels. It is worth noting that thermomechanical processing with accelerated cooling can produce the same structure in low-carbon steels [5]. Therefore, tempforming and ausforming allow obtaining a superior combination of strength and toughness in low-alloyed steels. In particular, the tempformed steels exhibit delamination phenomenon, which improves the toughness at low temperatures [14-16]. Delamination results from anisotropic microstructures, i.e., the grains/subgrains highly elongated along the rolling direction $(\mathrm{RD})$ and the second phase particles precipitated at the longitudinal grain/subgrain boundaries. Delamination was observed in various structural steels and alloys [12,17-29], leading to so-called delamination toughening. The delamination toughening can decrease DBTT in low-alloy steels by reducing the triaxial stress concentration at the crack tip [18-22,25,26]. The dominating factors controlling the delamination toughening are considered to be the ultrafine grains, the grain shape and the $\langle 110\rangle \| \mathrm{RD}$ fiber texture [9,13,22,23,29-31], which vary depending on the starting microstructure $[9,23]$ and the

\footnotetext{
* Corresponding author.

E-mail address: yanushkevich@bsu.edu.ru (Z. Yanushkevich).
} 

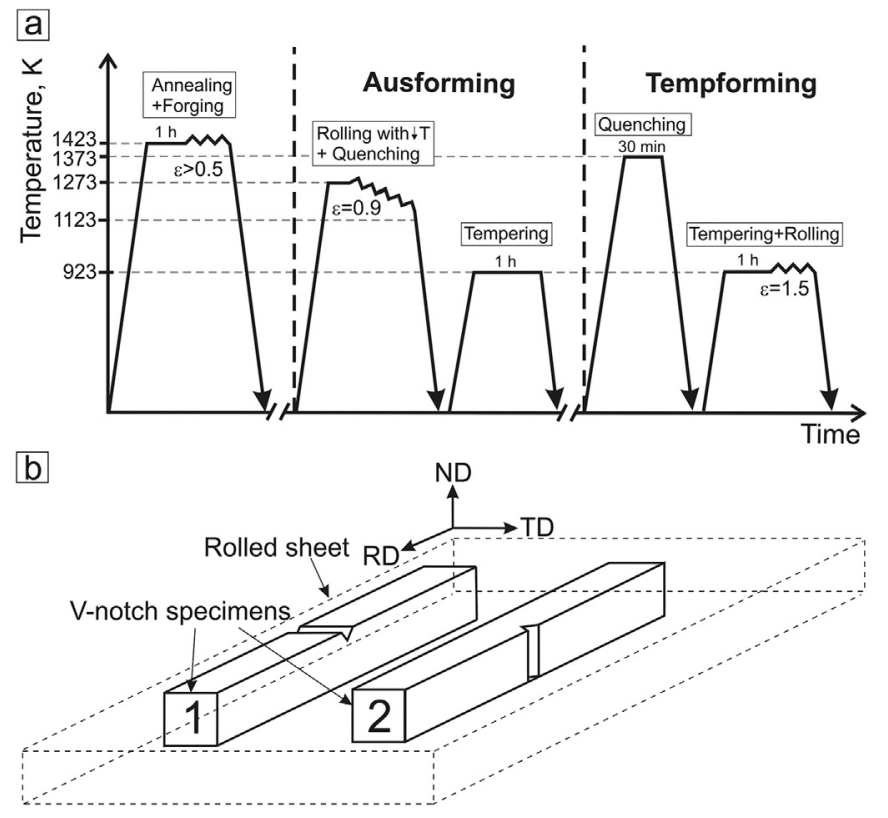

Fig. 1. Schematic diagrams illustrating the routes of thermo-mechanical processing (a) and the specimen orientations for impact tests (b)

processing conditions, such as rolling temperature and rolling reduction $[9,22]$.

The aim of the present paper is to study the effect of thermo-mechanical processing route on the fracture toughness of an S700MC-type low-alloy steel over a range of temperatures from $293 \mathrm{~K}$ to $77 \mathrm{~K}$. In order to understand the underlying mechanisms of fracture, the microstructure and mechanical properties of the steel subjected to tempforming and ausforming were comparatively analyzed.

\section{Experimental}

A high-strength low-alloy steel of S700MC-type with a chemical composition of $\mathrm{Fe}-0.09 \mathrm{C}-0.12 \mathrm{Si}-1.19 \mathrm{Cr}-1.55 \mathrm{Mn}-0.003 \mathrm{P}-.005 \mathrm{~S}$ $-0.05 \mathrm{Nb}-0.025 \mathrm{Al}-0.05 \mathrm{Ti}-0.42 \mathrm{Mo}-0.09 \mathrm{~V}-0.003 \mathrm{~B}$ (all in mass\%) was subjected to homogenization annealing followed by hot forging at a temperature of $1423 \mathrm{~K}$. Two different routes of thermo-mechanical processing were chosen (Fig. 1a). The first method was ausforming consisting of rolling with decreasing temperature from $1273 \mathrm{~K}$ to $1123 \mathrm{~K}$ to a total strain of 0.9 followed by quenching and tempering at $923 \mathrm{~K}$ for $1 \mathrm{~h}$. The second method included quenching from $1373 \mathrm{~K}$, tempering at $923 \mathrm{~K}$ for $1 \mathrm{~h}$ and rolling at tempering temperature (tempforming) to a total strain of 1.5.

The structural observations were performed on the RD-ND sections ( $\mathrm{RD}$ is the rolling direction, ND is the normal direction), using a Quanta Nova Nanosem 450 scanning electron microscope (SEM) with an electron back scattering diffraction (EBSD) analyzer incorporating an orientation imaging microscopy (OIM) system and a Jeol JEM 2100 transmission electron microscope (TEM). The samples for structural characterizations were electro-polished using an electrolyte containing $10 \%$ perchloric acid and $90 \%$ acetic acid at a voltage of $20 \mathrm{~V}$ at room temperature. The OIM images were subjected to clean up procedure setting minimal confidence index of 0.1 . The mean grain size was evaluated on the OIM micrographs as an average distance between high-angle boundaries with misorientations of $\theta \geq 15^{\circ}$. In addition to OIM, the misorientations between the grains/subgrains were analyzed by the conventional TEM Kikuchi line method using the convergedbeam technique [31]. The lath/subgrain sizes were measured on TEM micrographs by the liner intercept method, including all clear visible boundaries and subboundaries. The dislocation density was evaluated by counting individual dislocations inside the laths/subgrains on representative TEM images.

Tensile tests were carried out using an Instron 5882 testing machine. The tensile specimens with gauge dimensions of $12 \mathrm{~mm}$ in length, $3 \mathrm{~mm}$ in width, $1.5 \mathrm{~mm}$ in thickness were prepared with the tensile direction along $\mathrm{RD}$. The specimens were tested at ambient temperature at a crosshead rate of $2 \mathrm{~mm} / \mathrm{min}$. Standard Charpy V-notch specimens were tested using an Instron $450 \mathrm{~J}$ impact machine (Model SI-1M) with an Instron Dynatup Impulse data acquisition system at temperatures ranging from 77 to $293 \mathrm{~K}$. The specimens for impact test were cut out as shown in Fig. 1b, where the sample 1 is that for the impact direction along ND (impact test |ND) and the sample 2 is that for the impact along TD (impact test ||TD).

\section{Results}

\subsection{Microstructure characterization}

Typical microstructures of the present steel subjected to different treatments are shown in Fig. 2. The structural parameters for the S700MC-type steel samples after ausforming and tempforming are summarized in Table 1. The ausforming resulted in the development of tempered martensite lath structure, in which prior austenite grains are subdivided into packets and blocks of martensite laths [10] (Fig. 2a). The mean sizes of the prior austenite grains and martensite blocks are about $20 \mu \mathrm{m}$ and $1.5 \mu \mathrm{m}$, respectively. On the other hand, the tempforming led to the evolution of ultrafine grained microstructure consisting of grains elongated along $\mathrm{RD}$. The mean transverse grain size is $530 \mathrm{~nm}$ (Fig. 2b). The tempformed steel is characterized by strong $\langle 001\rangle \|$ ND and $\langle 111\rangle||$ ND fiber textures (corresponding to red and blue colors, respectively, in Fig. 2b). It was shown that intensity of the $\{100\}\langle 110\rangle$ texture increases in low-carbon steels during multi-pass warm plate rolling at temperatures of $813-923 \mathrm{~K}[13,28]$. Indeed, the highest relative intensity of 5 was obtained for $\langle 001\rangle$ ||ND texture component.

The TEM images of the S700MC-type steel subjected to ausforming and tempforming are shown in Figs. 2c and 2d. The ausformed microstructure consists of elongated martensite laths with rather high dislocation density of $5 \times 10^{14} \mathrm{~m}^{-2}$. The transverse lath size comprises approx. $200 \mathrm{~nm}$ and the misorientations between the laths are mostly below 3 degrees (Fig. 2c). The tempforming resulted in the development of thin lamellar structure with an average transverse subgrain size of $100 \mathrm{~nm}$ and the dislocation density of $8 \times 10^{14} \mathrm{~m}^{-2}$. The boundaries between the elongated grains/subgrains are represented by a mixture of low-to-high angle (sub)boundaries (Fig. 2d). It is worth noting that there are many subboundaries with relatively large misorientations close to $15^{\circ}$. The laths developed by quenching and tempering further increase their misorientations during tempforming, i.e., warm rolling at $923 \mathrm{~K}$ to a total true strain of 1.5. The main difference between two structural conditions consists in the size and shape of the blocks being aggregations of the laths with the same crystallographic orientation. Tempforming provides lamellar block shape and refines the thickness of blocks.

Both ausformed and tempformed microstructures are characterized by the formation of dispersed carbides at various boundaries/subboundaries of laths, blocks, packets and prior austenite grains. Typical examples of $\mathrm{Cr}_{23} \mathrm{C}_{6}$-type carbides are shown in Figs. 3a and 3b. In addition, $\mathrm{M}(\mathrm{C}, \mathrm{N})$ carbonitrides with an average size of $10 \mathrm{~nm}$ precipitate throughout the tempered martensite. As shown on Fig. 3c the carbide particle sizes range from 7 to $160 \mathrm{~nm}$, and an average size is about $50 \mathrm{~nm}$ after both treatments. It is clearly seen that the particle size distributions have maximums in the range of $40-50 \mathrm{~nm}$ irrespective of ausforming/tempforming treatment, although tempforming provides more homogeneous carbide distribution (sharper peak in Fig. 3c). It should be noted that the precipitations in the present steel samples and those evolved in low-carbon steels subjected to the thermo-mechanical control process are nearly the same [5]. 

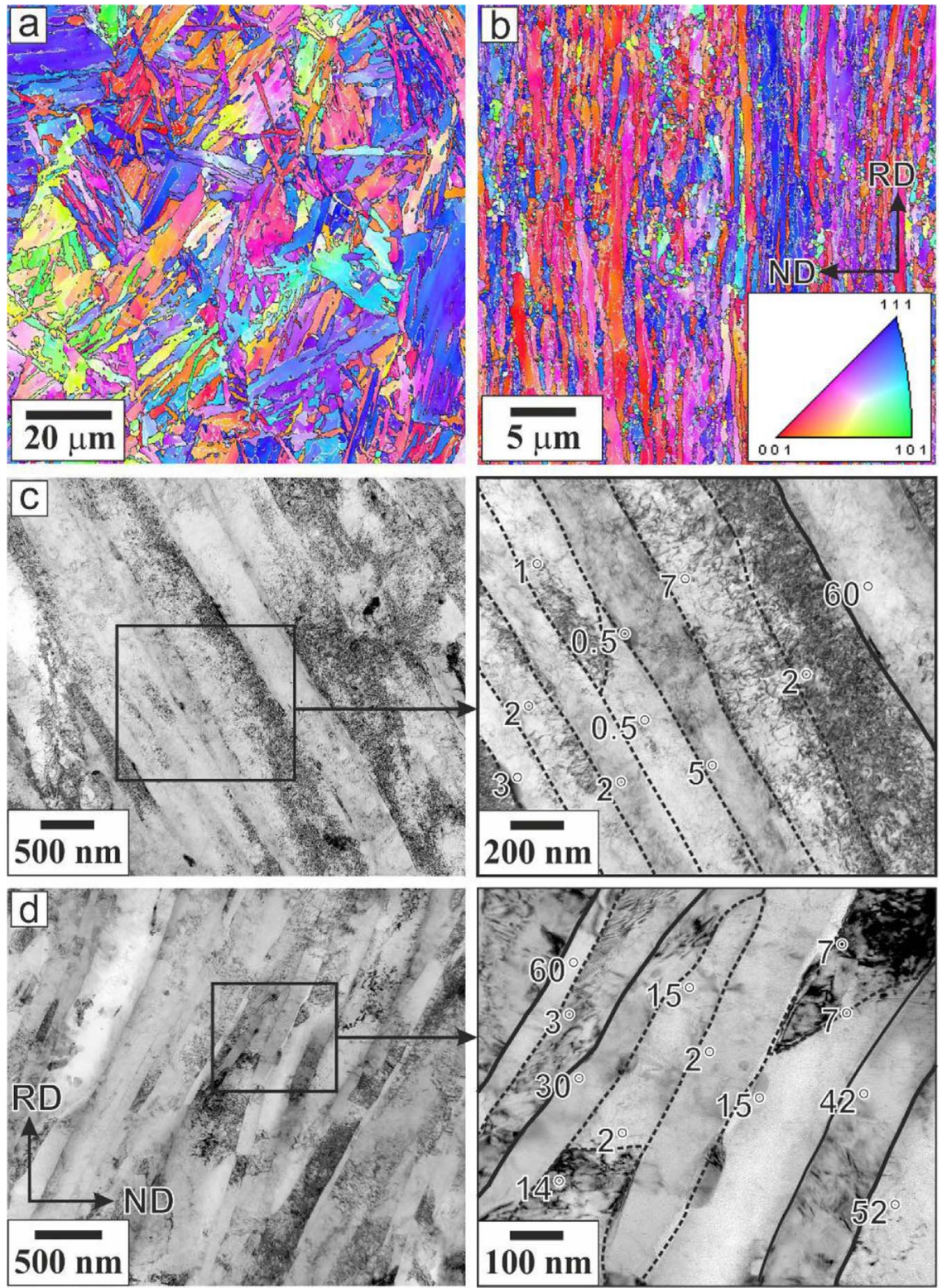

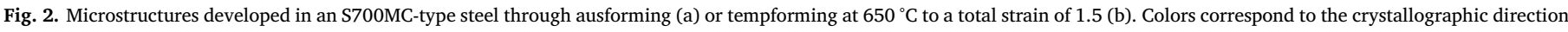

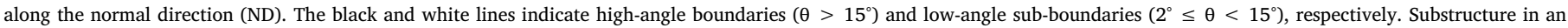
S700MC-type steel after ausforming (c) and tempforming (d). The numbers indicate the boundary misorientations.

Table 1

Structural parameters of an S700MC-type steel processed by ausforming or tempforming.

\begin{tabular}{lllll}
\hline Treatment & $\begin{array}{l}\text { High-angle } \\
\text { boundary } \\
\text { spacing, } \mu \mathrm{m}\end{array}$ & $\begin{array}{l}\text { Transverse } \\
\text { lath size, } \mathrm{nm}\end{array}$ & $\begin{array}{l}\text { Dislocation } \\
\text { density, } \times 10^{14} \\
\mathrm{~m}^{-2}\end{array}$ & $\begin{array}{l}\text { Mean } \\
\text { carbide } \\
\text { size, nm }\end{array}$ \\
\hline $\begin{array}{l}\text { Ausforming } \\
\text { Tempforming }\end{array}$ & 1.5 & 203 & 5 & 55 \\
\hline
\end{tabular}

\subsection{Tensile properties}

The engineering stress-strain $(\sigma-\varepsilon)$ curves obtained for a S700MCtype steel samples by tension at ambient temperature are presented in Fig. 4. After ausforming the $\sigma-\varepsilon$ curve exhibits a noticeable strain hardening followed by an apparent steady-state flow with a quite low work-hardening rate. Relatively large strains after the onset of plastic instability and necking are observed in the both material conditions. Following the onset of plastic flow, the tempformed specimen exhibits a negligible short stage of strain hardening and a well-defined peak stress followed by a plateau that is discontinuous yielding $[3,32,33]$.

The tensile properties of the ausformed steel are characterized by relatively high ultimate tensile strength and yield strength of 980 and $910 \mathrm{MPa}$, respectively. These high strength properties are combined with satisfactory plasticity; total elongation is about $13 \%$. The tempforming significantly enhances the strength owing to the formation of ultrafine grain layered structure. The ultimate tensile strength and yield strength are almost the same and comprise 1110 and $1090 \mathrm{MPa}$, respectively. An increase in the strength after tempforming is accompanied by a decrease in total elongation to $9 \%$. The values of yield strength, ultimate tensile strength and total elongation are shown in Table 2.

\subsection{Impact toughness}

The specimens after impact tests are shown in Fig. 5. It is seen that cracks propagated directly across the central portions of the Charpy 

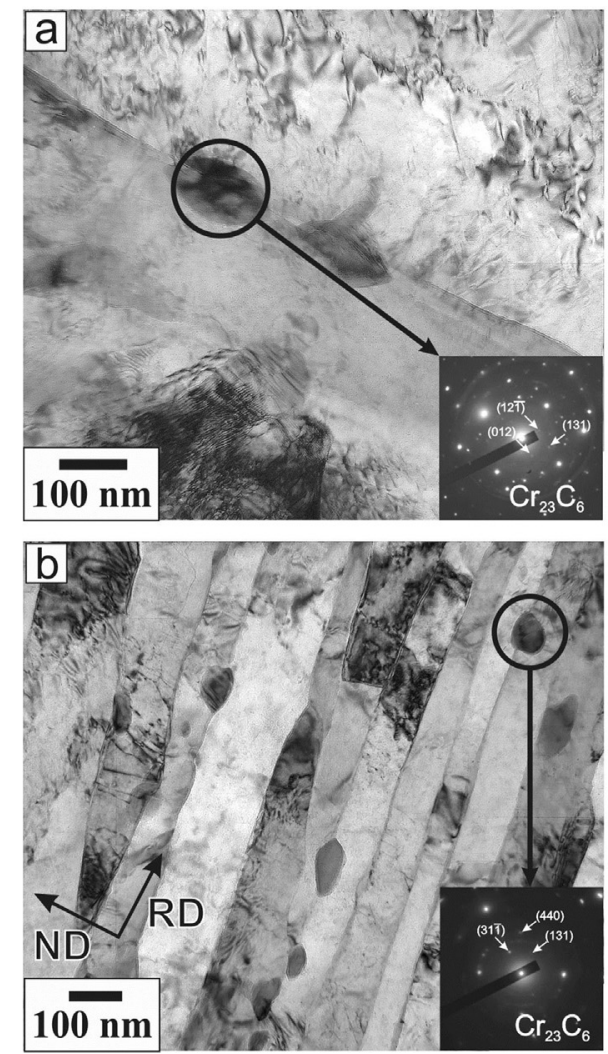

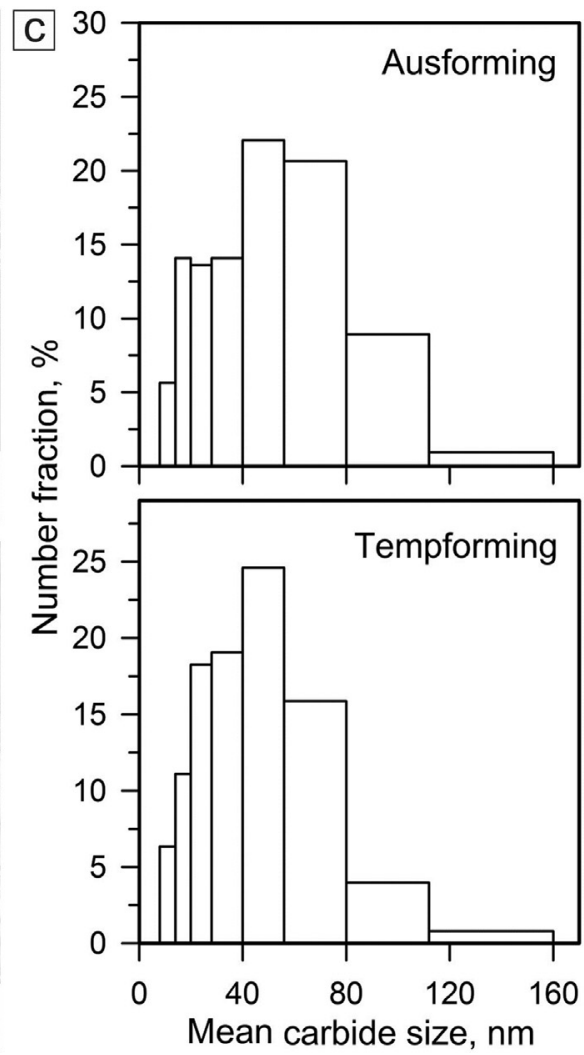

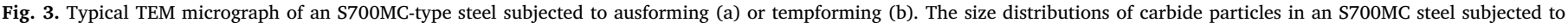
different treatments (c).

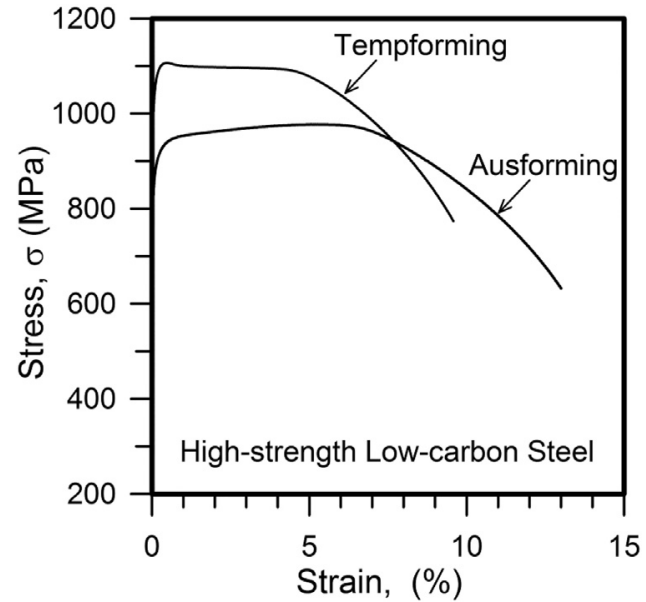

Fig. 4. Room temperature tensile curves of an S700MC-type steel subjected to different treatments.

Table 2

Mechanical properties of an S700MC-type steel subjected to ausforming or tempforming.

\begin{tabular}{llll}
\hline Treatment & $\begin{array}{l}\text { Offset yield strength, } \\
\mathrm{MPa}\end{array}$ & $\begin{array}{l}\text { Ultimate tensile } \\
\text { strength, MPa }\end{array}$ & Elongation, \% \\
\hline Ausforming & 910 & 980 & 13 \\
Tempforming & 1090 & 1110 & 9
\end{tabular}

specimens for impact test IID at all temperatures in the tempformed condition and at $77 \mathrm{~K}$ in the ausformed condition. The Charpy specimens in the tempformed condition exhibit delaminations, i.e., the cracks branch along the impact test specimens, and zigzag-shaped cracks appear. The Charpy specimen in the tempformed conditions did not separate into two pieces after impact test $\| \mathrm{ND}$ at $293 \mathrm{~K}$. Even at liquid nitrogen temperature, the crack propagation crosswise to the impact specimen is suppressed.

Series of load vs displacement and absorbed energy vs displacement curves obtained by the impact tests of the steel subjected to ausforming and tempforming are shown in Fig. 6 with indication of the characteristic points of general yield load $\left(\mathrm{P}_{\mathrm{GY}}\right)$, maximum load $\left(\mathrm{P}_{\mathrm{m}}\right)$, fast fracture load $\left(\mathrm{P}_{\mathrm{F}}\right)$ and arrest load $\left(\mathrm{P}_{\mathrm{A}}\right)$ [34-39]. The sample subjected to ausforming and tested at room temperature exhibits high V-notch impact adsorbed energy of $140 \mathrm{~J}$. The displacement range exceeds the size of the central portion of the impact specimen that is characteristic of a fracture when the crack propagation path before the separation of the sample into two parts is much larger than the sample thickness [13,34-39]. The arrest load after the fast fracture propagation takes place at a displacement of about $7 \mathrm{~mm}$. The total fracture energy is mostly consumed during the initiation of crack with critical dimension and the stage of stable crack propagation. A decrease in the test temperature shortens the stage of stable crack propagation. In the temperature range of $233-293 \mathrm{~K}$, the $\mathrm{P}_{\mathrm{GY}}$ and $\mathrm{P}_{\mathrm{m}}$ values are almost the same. The large displacement interval from $\mathrm{P}_{\mathrm{GY}}$ to $\mathrm{P}_{\mathrm{m}}$ provides a high value for impact adsorbed energy. At $183 \mathrm{~K}$, the onset of unstable crack propagation occurs just after the maximum load. At $77 \mathrm{~K}$, the onset of unstable fracture takes place after insignificant plastic deformation; the steel is fully brittle. In contrast to a common tendency of an increase in PGY and Pm with a decrease in the impact test temperature, the maximal load decreases by a factor of 5 with a decrease in the test temperature from 183 to $77 \mathrm{~K}$.

The impact behavior of the tempformed samples is quite different from that of ausformed samples. The specimens for impact test IND exhibit all four stages of crack propagation at $\mathrm{T}>183 \mathrm{~K}$. The $\mathrm{P}_{\mathrm{m}}$ values are remarkable higher than $\mathrm{P}_{\mathrm{GY}}$. The stages of stable and unstable crack propagations are typical for delamination toughness; the alternation of crack re-initiation points and arrest points is attributed to 


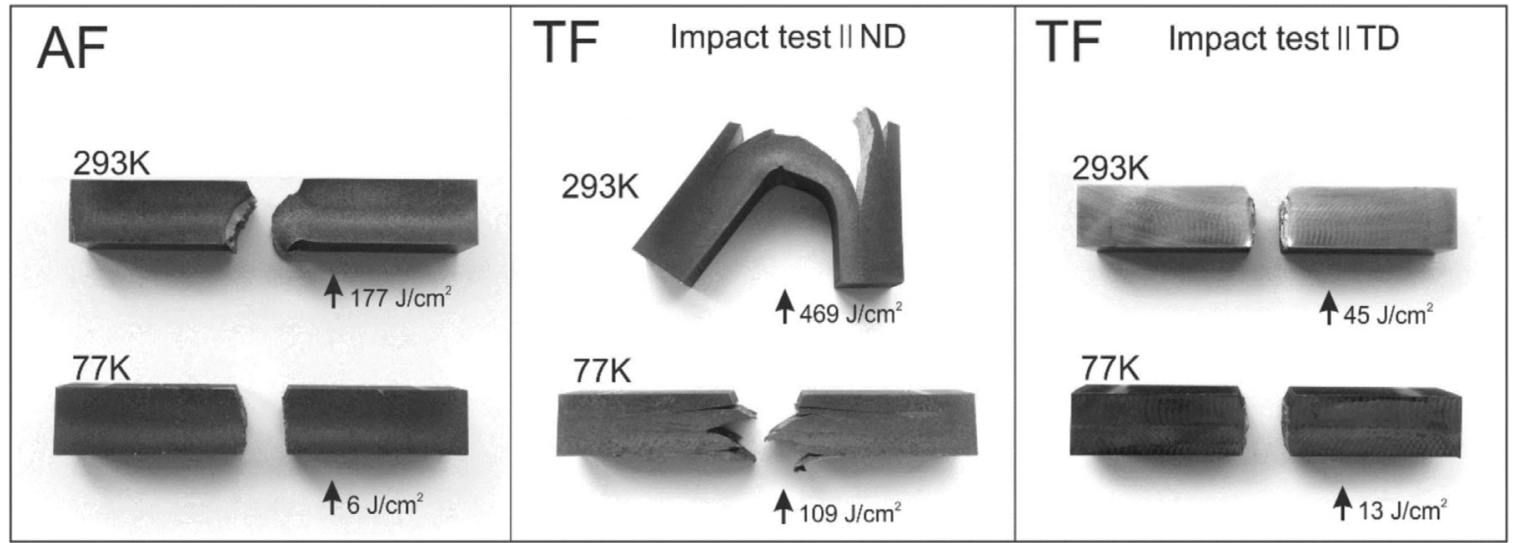

Fig. 5. Charpy V-notched specimens after impact tests. The steel was subjected to ausforming (AF) or tempforming (TF). The arrows indicate the impact direction.
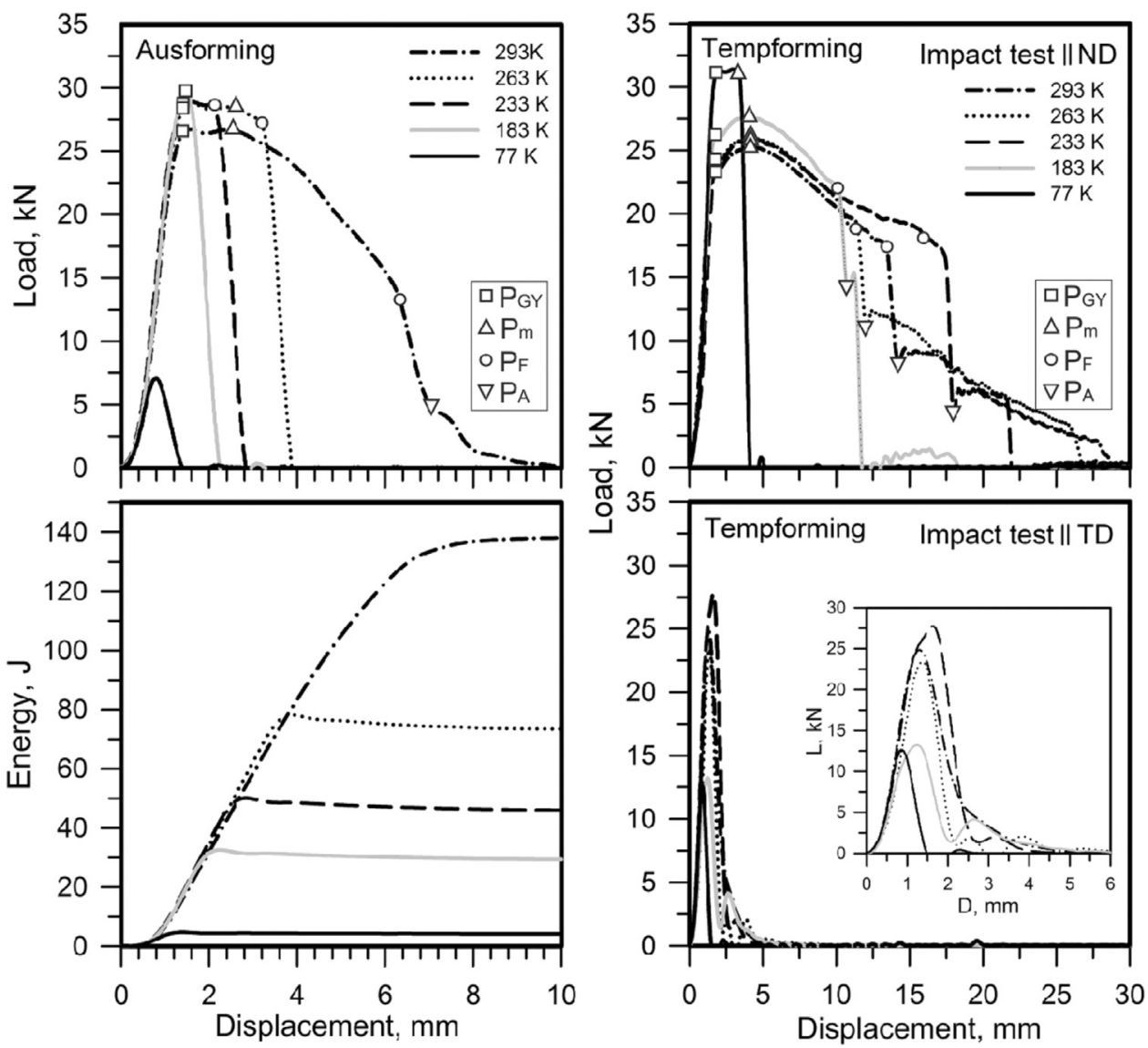

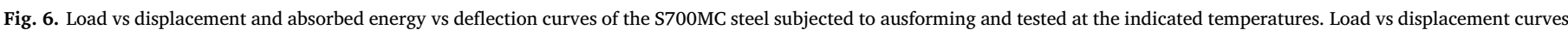
of the tempformed S700MC steel after impact test in two directions (impact test ||ND and impact test ||TD) at the indicated temperatures.

zigzag crack deflection and secondary cracks running perpendicular to the impact direction [27]. The onset of unstable crack propagation occurs after rather large stage of stable crack propagation. A short stage of the arrest of unstable crack propagation is observed even at $183 \mathrm{~K}$. At $77 \mathrm{~K}$, the onset of unstable crack propagation appears at the maximum load. A decrease in the test temperature leads to an increase in the $\mathrm{P}_{\mathrm{GY}}$ and $\mathrm{P}_{\mathrm{m}}$ values. On the other hand, the onset of unstable crack propagation occurs right after the maximal load during the impact tests ||TD in the studied temperature range.

The Charpy V-notch impact absorbed energy of the S700MC-type steel subjected to different treatments is shown in Fig. 7. The value of impact toughness of the ausformed samples is $177 \mathrm{~J} / \mathrm{cm}^{2}$ at room temperature and $98 \mathrm{~J} / \mathrm{cm}^{2}$ at $263 \mathrm{~K}$. Further decrease of the test temperature results in a gradual decrease in the impact toughness to $42 \mathrm{~J} / \mathrm{cm}^{2}$ at $183 \mathrm{~K}$, and then the absorbed energy falls to $6 \mathrm{~J} / \mathrm{cm}^{2}$ at $77 \mathrm{~K}$. The last value corresponds to lower shelf energy [34-39], whereas upper shelf energy should be higher than $177 \mathrm{~J} / \mathrm{cm}^{2}$ at $293 \mathrm{~K}$. Therefore, the ductile-brittle transition takes place at approx. $273 \mathrm{~K}$. The Charpy test specimens from the tempformed steel were not completely broken at $\mathrm{T} \geq 233 \mathrm{~K}$ after impact tests $\| \mathrm{ND}$. Therefore, the real values of the V-notch impact energy at these temperatures should be higher than indicated in Fig. 7. These specimens exhibit superior delamination toughness. The high impact energy of $109 \mathrm{~J} / \mathrm{cm}^{2}$ is obtained even at liquid nitrogen temperature. In contrast, the Charpy V-notch impact energy of the tempformed steel obtained by the impact tests ||TD lies at lower shelf of ductile-brittle transition. In this case, DBTT seems to be 


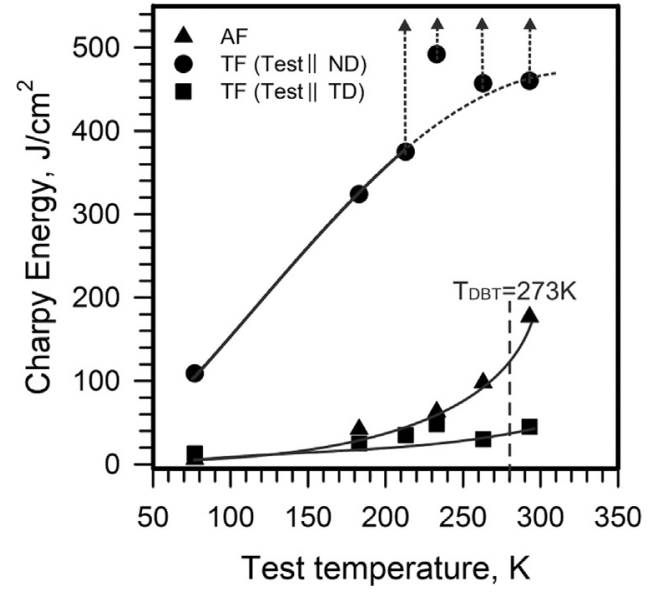

Fig. 7. Effect of test temperature and direction (impact test ||ND and impact test ||TD) on the impact toughness of an S700MC-type steel subjected to ausforming (AF) or tempforming (TF). The arrows indicate non-fractured specimens.

above $293 \mathrm{~K}$.

\subsection{Fractography}

The low- and high-magnification SEM images of the impact fracture surfaces of the ausformed specimens are shown in Figs. 8 to 10. A viscous fracture can be observed at room temperature, the fraction of ductile fracture is about 0.83 as calculated by a ratio of ductile fracture area to total one (The areas of ductile fracture are outlined by dashed lines in Fig. 8). The fracture surface consists of the initiation, stable crack propagation, unstable crack propagation and shear lip zones [34-39]. The dimpled transgranular fracture, which results from the coalescence of microvoids, is observed in the initiation, stable crack propagation and shear lip zones. These zones are distinguished by the dimple shapes. The shallow dimples are in dominant in the initiation zone, where fine dimples alternate with rather coarse ones. In contrast, the uniform distribution of dimples with conical shape is observed in the shear lip zone. Individual particles located on the dimple bottom suggest the microvoid nucleation on the particles [40]. The stable crack propagation occurs in an essentially ductile manner, when the absorbed energy can be related to the dimple aspect ratio, i.e., depth/diameter ratio, through a linear function [41]. Fracture in the zone of unstable crack propagation occurs by quasi-cleavage transgranular mechanisms, while the fine dimples can only be found on rare tear ridges.

The zone of unstable crack propagation expands while other zones shorten with a decrease in the impact test temperature. The quasicleavage transgranular fracture is observed in the zone of unstable
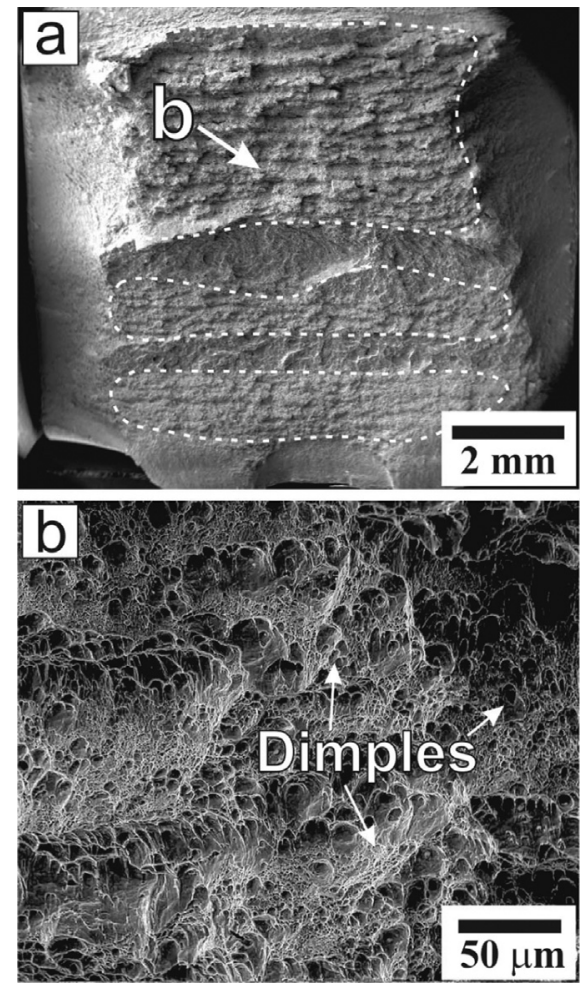

Fig. 8. Fracture surface of the Charpy V-notch specimen of the ausformed S700MC-type steel tested at $293 \mathrm{~K}$; general view (a) and high magnification of the indicated portion (b).

crack propagation and the shear lip zone at $233 \mathrm{~K}$, although the latter contains small amount of the fine dimples on tear ridges (Fig. 9). The shear lip zone can hardly be observed at $183 \mathrm{~K}$. Therefore, decreasing the temperature suppresses the arrest of unstable crack propagation. The zones of stable crack propagation are distinguished as areas of quasi-cleavage fracture alternating with large areas of fine dimples. These zones of stable crack propagation provide $\mathrm{KCV}>20 \mathrm{~J} / \mathrm{cm}^{2}$ despite the negligible portion of shear in the fracture surface. At $77 \mathrm{~K}$, the quasi-cleavage fracture is observed on the whole fracture surface (Fig. 10). The onset of unstable crack propagation occurs immediately after contact between the pendulum and the Charpy test specimen.

The SEM images of impact fracture surfaces of the tempformed specimens after impact tests $\| \mathrm{ND}$ at $293 \mathrm{~K}$ and $77 \mathrm{~K}$ are shown in Figs. 11 and 12, respectively.

The dimple fracture occurs during impact tests $\mid$ ND at $293 \mathrm{~K}$ at the initiation stage (Fig. 11b). Then, the stable crack propagation takes place that is associated with the delamination along RD-TD planes, i.e., crosswise to the impact direction, by transgranular cleavage (Fig. 11c).
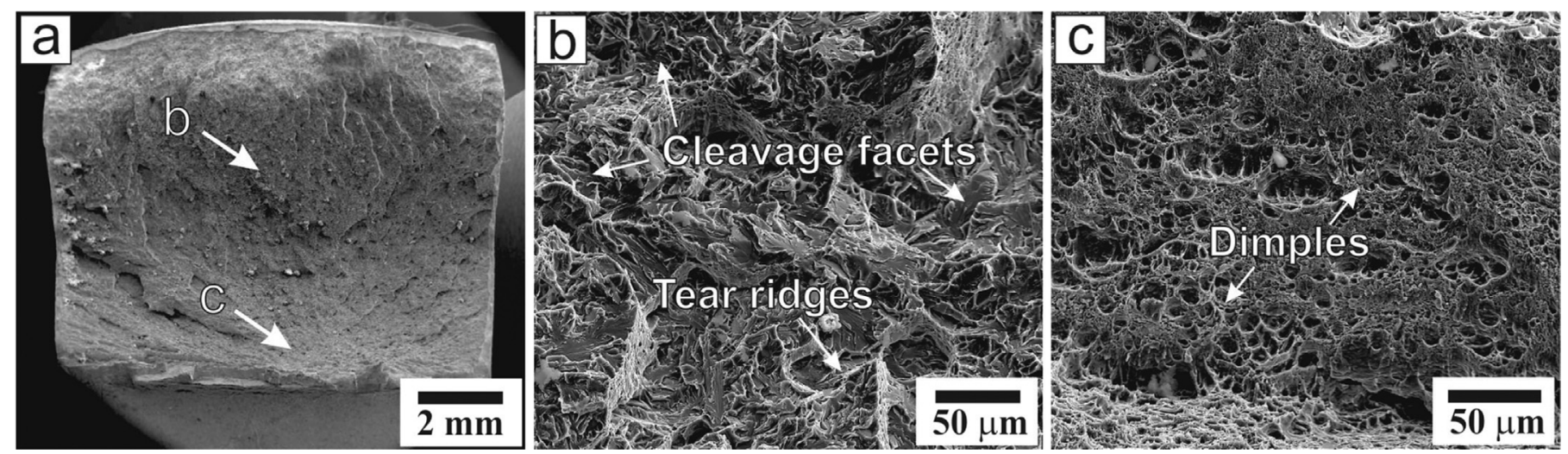

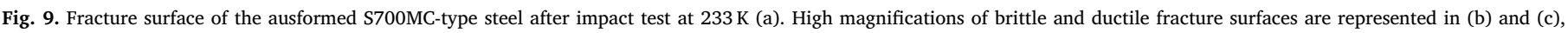
respectively. 

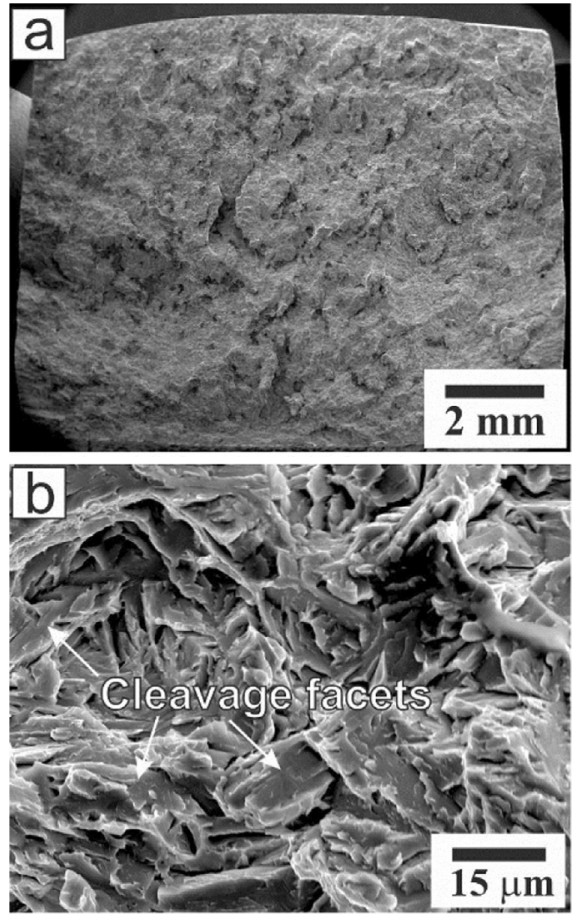

Fig. 10. Fracture surface in the Charpy V-notch specimen of the ausformed S700MC-type steel after test at $77 \mathrm{~K}$.

The fracture surface consists of almost flat terraces formed parallel to RD-TD plane $[17,42]$. The delamination cleavage frequently initiates on parallel cleavage $\{100\}$ planes lying almost parallel to the rolling plane $[17,20]$. An average dimension of terraces is approx. $200 \mu \mathrm{m}$. The stepwise terrace crack propagation belongs to crack arrester-type delamination [17]. The presence of elongated grains with $\langle 111\rangle|| N D$ in the tempformed structure restricts the crack propagation along $\{100\}$ planes and promotes the crack branching. It is worth noting that dimple fracture dominates on the planes normal to the delaminated layers (Fig. 11d). Thus, a very high V-notch absorbed energy during the impact tests ||ND of the tempformed steel is attributed to the arrest of crack propagation in cleavage manner along the rolling plane and ductile fracture in perpendicular direction. Decreasing the impact test temperature leads to anisotropy in the dimensions of delamination terraces (Fig. 12a). Their dimension along TD increases, while that in $\mathrm{RD}$ decreases. At $77 \mathrm{~K}$, the dimple fractures are observed in the local areas of initiation stage and tear ridges between the areas of quasicleavage fracture (Fig. 12b). It is apparent that the zigzag crack propagation provides relatively high impact energy despite of hindering ductile fracture even at $77 \mathrm{~K}$.

The fracture surfaces of the tempformed S700MC-type steel after impact test $\| \mathrm{TD}$ at $293 \mathrm{~K}$ and $77 \mathrm{~K}$ are shown in Fig. 13. The main feature of fracture surfaces is intergranular cleavage fracture along the impact direction irrespective of test temperature. The deep splits propagate along the rolling plane, i.e., normal to the impact direction (Figs. 13a and 13d). The small dimples are observed at the ridges between these splits (Figs. 13b and 13e). The distinct sawtooth fracture profiles are observed (Figs. 13c and 13f). The depth of intergranular splits decreases while their density increases as the impact test temperature decreases. Moreover, the areas of shear lip zones reduce with temperature. Thus, the fracture of the tempformed steel during the impact tests ||TD occurs mainly through intergranular cleavage mechanism. However, final separation of the Charpy specimen occurs by ductile transgranular fracture at ridges and in the shear lip zone, providing the fracture toughness of $\mathrm{KCV}>25 \mathrm{~J} / \mathrm{cm}^{2}$ at $\mathrm{T} \geq 183 \mathrm{~K}$.

\section{Discussion}

The tempered martensite in the ausformed steel is characterized by relatively small high-angle boundary spacing and high dislocation density. This microstructure improves the mechanical properties such
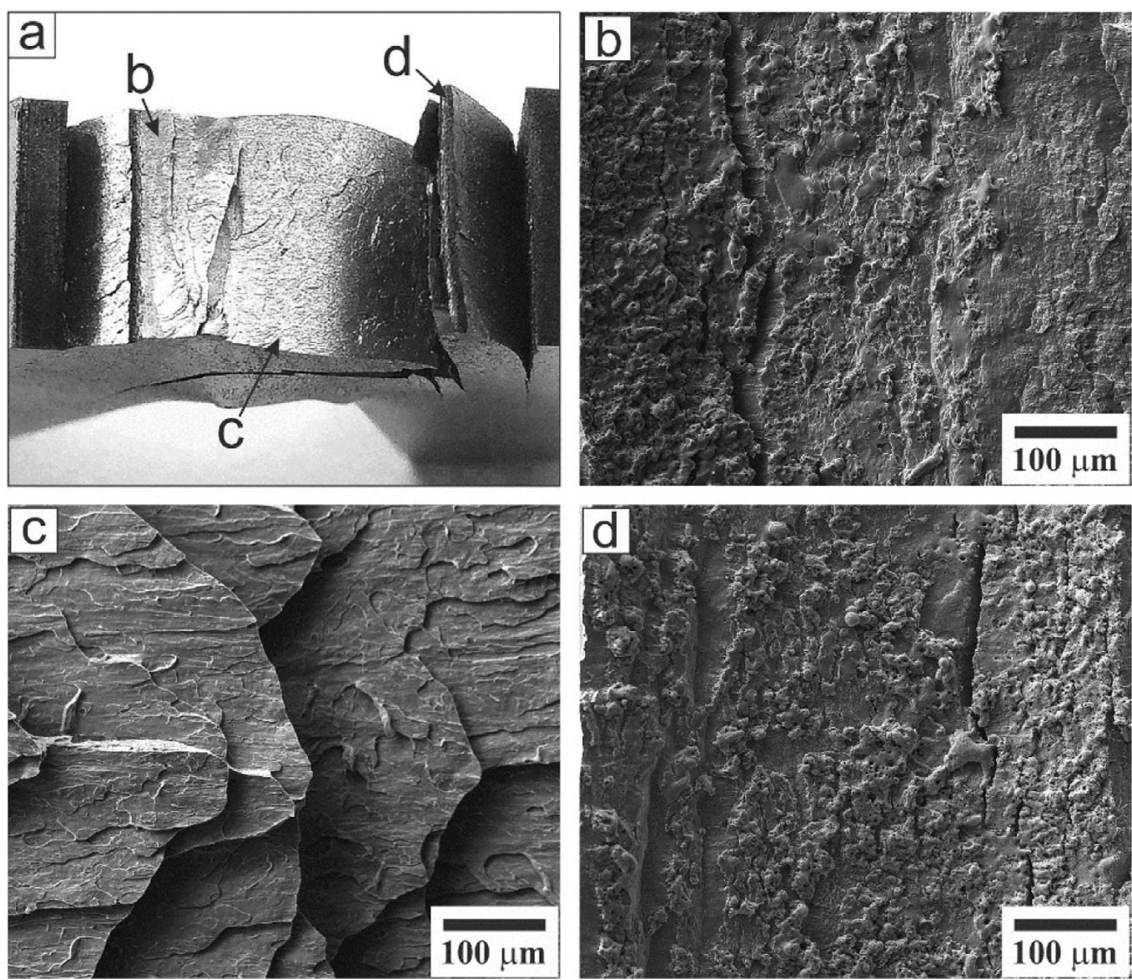

Fig. 11. Fracture surface of the tempformed specimen after impact test $\| \mathrm{ND}$ at $293 \mathrm{~K}$; general view of tested sample (a) and high magnifications of indicated portions (b to d). 

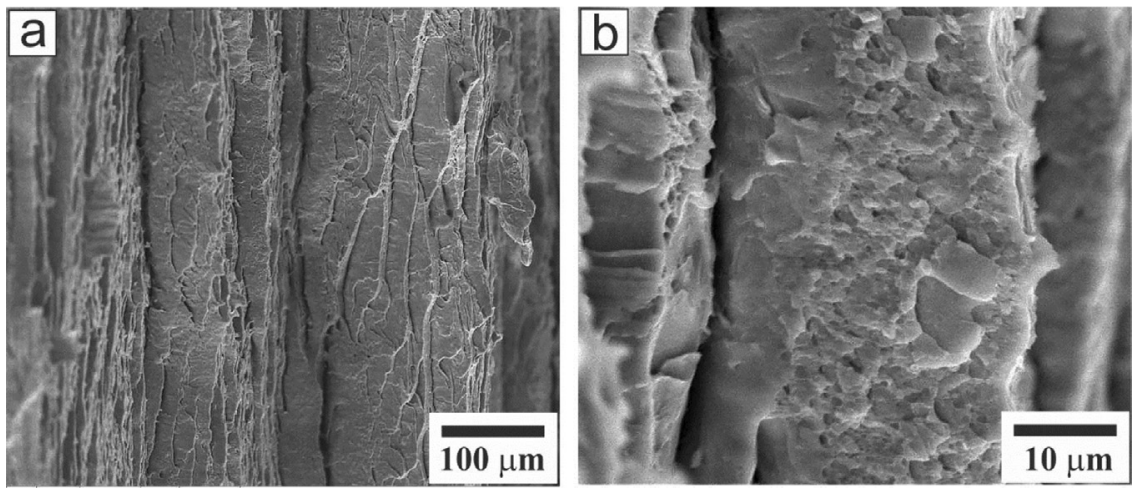

Fig. 12. Fracture surface of the tempformed specimen after impact test $\| \mathrm{ND}$ at $77 \mathrm{~K}$; delaminated layers (a) and portion of ductile fracture (b).

as yield strength, ductility and V-notch impact energy. The latter increases by a factor of 2 in comparison with the data sheet properties for S700MC steel after conventional thermo-mechanical processing [43]. On the other hand, the tempforming produces structure with laminar morphology (Fig. 14). The distance between high-angle boundaries along ND and the lath thickness are significantly reduced, the thickness of layers and blocks in the ND direction is almost the same. Thus, the main difference between steels subjected to ausforming or tempforming is the difference in the block dimensions. The block size in the lath martensite structure can be considered as the effective grain size that controls the steel cleavage [8]. The refinement of martensite blocks is very effective in an increase of resistance to transgranular cleavage fracture. Moreover, the ductile-brittle transition temperature depends on the block size and tends to decrease with decreasing the block dimensions [8].

The fracture mechanisms operating in the ausformed steel are typical for steels with tempered martensite lath structures [36,37]. The toughness is provided by stable crack propagation in ductile manner. Decreasing temperature facilitates quasi-cleavage fracture and decreases the impact plane-strain fracture toughness that leads to transition from stable crack propagation to unstable one at smaller displacements [36-38]. Generally, steels with an impact strength below $28 \mathrm{~J}$ are considered as brittle ones [43]. Therefore, embrittlement upon decreasing the temperature can be characterized by a transition temperature $\left(\mathrm{T}_{28 \mathrm{~J}}\right)$, which corresponds to critical impact strength of $28 \mathrm{~J}$ [34]. The temperature of $\mathrm{T}_{28 \mathrm{~J}}$ is below $183 \mathrm{~K}$ for the ausformed S700MC steel. Therefore, the ausformed steel can be considered tough down to cryogenic temperatures.

The fracture behavior of the tempformed S700MC steel is completely different. It is known that the formation of laminar structure provides two basic geometries for the crack propagation, i.e., crack divider and crack arrester [42]. The weak interfaces arrange parallel to the rolling plane and the stresses generated by local plastic incompatibilities at the notch and/or the crack tip causes delaminations [42]. However, the effect of such delamination on the impact toughness is quite different for the impact tests ||ND and the impact tests ||TD. In the case of impact test IND, the delamination results from the crack propagation occurring in brittle transgranular manner in the crack
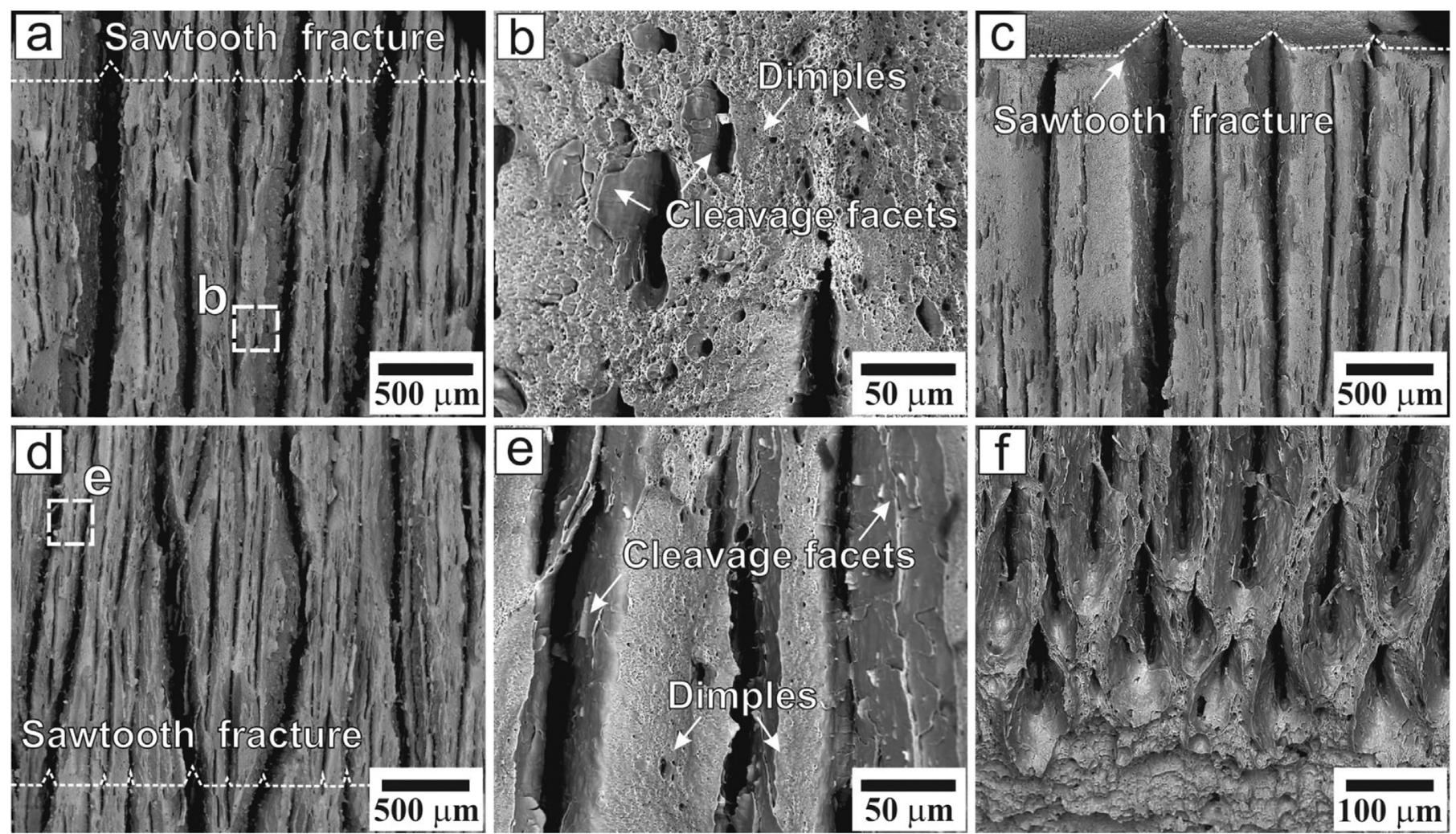

Fig. 13. Fracture surfaces of the tempformed S700MC-type steel after impact tests ॥TD at $293 \mathrm{~K}$ (a to c) and $77 \mathrm{~K}$ (d to f). 

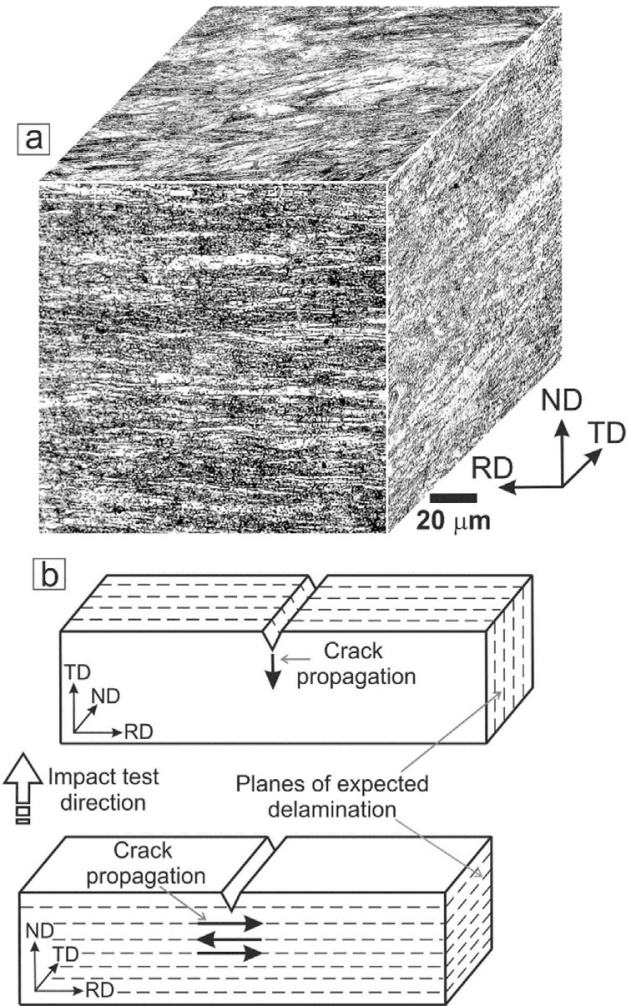

Fig. 14. General view of the structure on three orthogonal sections (a) and schematic illustration of layered geometry showing delamination toughening (b).

divider orientation direction. The delamination along the weak interfaces divides the main crack, which propagated along the impact direction, into numerous cracks propagating in perpendicular direction (Fig. 14). This type of delamination has been suggested to result in transition from triaxial stress at the crack tip to biaxial planar stress that hinders the propagation of the main crack [42]. Both the fine martensite blocks and the biaxial planar stress conditions provide an effective arrest of crack propagation along the impact direction and result in superior toughness even at cryogenic temperatures. In contrast, the delamination along the weak interfaces creates easy paths for the crack propagation along the impact direction during the impact tests ॥TD (Fig. 14).

The easy crack propagation occurring in intergranular manner along the limited number of weak interfaces is ahead of ductile transgranular fracture. The impact toughness is controlled by the pan-caked martensite blocks, which play a role of obstacles for crack propagation. As a result, the tempformed S700MC steel shows satisfactory toughness at ambient temperature and $\mathrm{T}_{28 \mathrm{~J}}$ of about $233 \mathrm{~K}$ for the impact tests ॥TD.

\section{Conclusions}

1. The present S700MC-type steel subjected to ausforming is characterized by the tempered martensite lath structure, whereas tempforming results in the formation of an ultrafine grain structure with an average transverse grain size of $530 \mathrm{~nm}$ and strong $\langle 111\rangle$ ||ND and $\langle 001\rangle|| N D$ fiber textures. The misorientations of dislocation subboundaries after tempforming are significantly larger than those among laths after ausforming. The latter ones do not exceed a few degrees, while the tempformed substructures frequently involve misorientations close to $15^{\circ}$. The microstructures after ausforming and tempforming are characterized by $\mathrm{Cr}_{23} \mathrm{C}_{6}$-type carbides with an average size of $50 \mathrm{~nm}$ precipitated along boundaries/subboundaries and homogeneously distributed $\mathrm{M}(\mathrm{C}, \mathrm{N})$ carbonitrides with an average size of $10 \mathrm{~nm}$.
2. The both ausforming and tempforming lead to high strength properties. The ultimate tensile strength of the steel subjected to ausforming or tempforming comprises $980 \mathrm{MPa}$ and $1110 \mathrm{MPa}$, respectively.

3. The ausformed steel exhibits fracture behavior typical for steels with tempered martensite lath structure. The V-notch impact energy at $293 \mathrm{~K}$ is $173 \mathrm{~J} / \mathrm{cm}^{2}$ and the temperature of $T_{28 \mathrm{~J}}$ is below $183 \mathrm{~K}$.

4. The tempformed steel exhibits extraordinary high impact toughness above $450 \mathrm{~J} / \mathrm{cm}^{2}$ at $293 \mathrm{~K}$ and of $109 \mathrm{~J} / \mathrm{cm}^{2}$ at $77 \mathrm{~K}$ upon the impact tests along the normal direction. This high fracture toughness is attributed to the delamination, when the fracture occurs by cleavage along the rolling plane with a large energy absorption.

5. The fracture toughness of the tempformed S700MC steel in the impact tests along the transverse direction is 45 and $13 \mathrm{~J} / \mathrm{cm}^{2}$ at $293 \mathrm{~K}$ and $77 \mathrm{~K}$, respectively. The fracture occurs by intergranular crack propagation along the impact direction at limited number of boundaries located crosswise to the rolling direction followed by ductile transgranular fracture at ridges and in the shear lip zone, providing satisfactory fracture toughness of above $28 \mathrm{~J} / \mathrm{cm}^{2}$ at temperatures of $\mathrm{T} \geq 233 \mathrm{~K}$.

\section{Acknowledgments}

Financial support was provided by the Russian Ministry of Education and Science (identifier RFMEFI57815X0139). Authors are grateful to staff of the Joint Research Center, Belgorod State University, for their assistance with instrumental analysis.

\section{References}

[1] T.V. Philip, T.J. McCaffrey, Ultrahigh-strength steels, ASM Int. Met. Handb. Tenth Ed. 1 (1990) 430-448.

[2] Y. Tomita, Development of fracture toughness of ultrahigh strength, medium carbon low alloy steels for aerospace applications, Int. Mater. Rev. 45 (2000) 27-37.

[3] G. Krauss, Steels: Processing Structure, and Performance, ASM International, USA, 2005.

[4] S. Takaki, K. Kawasaki, Y. Kimura, Mechanical properties of ultra fine grained steels, J. Mater. Process. Technol. 117 (2001) 359-363.

[5] K. Nishioka, K. Ichikawa, Progress in thermomechanical control of steel plates and their commercialization, Sci. Technol. Adv. Mater. 13 (2012) 023001.

[6] N. Tsuji, S. Okuno, Y. Koizumi, Y. Minamino, Toughness of ultrafine grained ferritic steels fabricated by ARB and annealing process, Mater. Trans. 45 (2004) 2272-2281.

[7] R. Song, D. Ponge, D. Raabe, Mechanical properties of an ultrafine grained C-Mn steel processed by warm deformation and annealing, Acta Mater. 53 (2005) 4881-4892.

[8] J.W. Morris, On the ductile-brittle transition in lath martensitic steel, ISIJ Int. 51 (2011) 1569-1575.

[9] Y. Kimura, T. Inoue, K. Tsuzaki, Tempforming in medium-carbon low-alloy steel, J. Alloy. Compd. 577 (2013) (S583-S542).

[10] H. Kitahara, R. Ueji, N. Tsuji, Y. Minamino, Crystallographic features of lath martensite in low-carbon steel, Acta Mater. 54 (2006) 1279-1288.

[11] N. Tsuji, R. Ueji, Y. Minamino, Y. Saito, A new and simple process to obtain nanostructured bulk low-carbon steel with superior mechanical property, Scr. Mater. 46 (2002) 305-310.

[12] A. Ohmori, S. Torizuka, K. Nagai, Properties of warm-rolled steel plates with ultrafine-grained ferrite and cementite structures, Tetsu-to-Hagane, J. Iron Steel Inst. Jpn. 89 (2003) 765-772.

[13] Y. Kimura, T. Inoue, F. Yin, K. Tsuzaki, Inverse temperature dependence of toughness in an ultrafine grain-structure steel, Science 320 (2008) 1057-1060.

[14] P. Shanmugam, S. Pathak, Some studies on the impact behavior of banded microalloyed steel, Eng. Fract. Mech. 53 (1996) 991-1005.

[15] B. Mintz, W. Morrison, Influence of fissures on tensile and fracture toughness of steels with ferrite/pearlite microstructures, Mater. Sci. Technol. 23 (2007) 1346-1356.

[16] W. Zhou, N. Loh, Effect of delaminations on improvement of notch toughness at low temperatures, Scr. Mater. 34 (1996) 633-639.

[17] Y. Kimura, T. Inoue, Combined effect of ausforming and warm tempforming on the strength and toughness of an ultra-high strength steel, ISIJ Int. 56 (2016) 2047-2056.

[18] J. Pilhagen, R. Sandström, Loss of constraint during fracture toughness testing of duplex stainless steels, Eng. Fract. Mech. 99 (2013) 239-250.

[19] M.S. Joo, D.-W. Suh, J.H. Bae, H.K.D.H. Bhadeshia, Role of delamination and crystallography on anisotropy of Charpy toughness in API-X80 steel, Mater. Sci. Eng. A 546 (2012) 314-322. 
[20] X. Min, Y. Kimura, T. Kimura, K. Tsuzaki, Delamination toughening assisted by phosphorus in medium-carbon low-alloy steels with ultrafine elongated grain structures, Mater. Sci. Eng. A 649 (2016) 135-145.

[21] Y. Kimura, T. Inoue, Influence of carbon content on toughening in ultrafine elon gated grain structure steels, ISIJ Int. 55 (2015) 1135-1144.

[22] Y. Kimura, T. Inoue, Y.I.N. Fuxing, K. Tsuzaki, Delamination toughening of ultrafine grain structure steels processed through tempforming at elevated temperatures, ISIJ Int. 50 (2010) 152-161.

[23] T. Inoue, F. Yin, Y. Kimura, K. Tsuzaki, S. Ochiai, Delamination effect on impact properties of ultrafine-grained low-carbon steel processed by warm caliber rolling, Metall. Mater. Trans. A 41 (2010) 341-355.

[24] J. Chao, C. Capdevila, Anisotropy in mechanical properties and fracture behavior of an oxide dispersion $\mathrm{Fe}_{2} 0 \mathrm{Cr}_{5} \mathrm{Al}$ alloy, Metall. Mater. Trans. A. 45 (2014) 3767-3780.

[25] A.L. Rouffié, P. Wident, L. Ziolek, F. Delabrouille, B. Tanguy, J. Crépin, A. Pineau, V. Garat, B. Fournier, Influences of process parameters and microstructure on the fracture mechanisms of ODS steels, J. Nucl. Mater. 433 (2013) 108-115.

[26] X.-L. Yang, Y.-B. Xu, X.-D. Tan, D. Wu, Influences of crystallography and delamination on anisotropy of Charpy impact toughness in API X100 pipeline steel, Mater. Sci. Eng. A 607 (2014) 53-62.

[27] A. García-Junceda, M. Hernández-Mayoral, M. Serrano, Influence of the microstructure on the tensile and impact properties of a 14Cr ODS steel bar, Mater. Sci. Eng. A 556 (2012) 696-703.

[28] D. Bourell, Cleavage delamination in impact tested warm-rolled steel, Metall. Trans. A 14 (1983) 2487-2496.

[29] Y. Kimura, T. Inoue, F. Yin, O. Sitdikov, K. Tsuzaki, Toughening of a 1500 MPa class steel through formation of an ultrafine fibrous grain structure, Scr. Mater. 57 (2007) 465-468.

[30] T. Inoue, Y. Kimura, S. Ochiai, Static fracture toughness of fail-safe steel, Scr. Mater. 65 (2011) 552-555.

[31] D.B. Williams, C.B. Carter, Transmission Electron Microscopy, Plenum Press, New York, 1996.
[32] R. Schwab, V. Ruff, On the nature of the yield point phenomenon, Acta Mater. 61 (2013) 1798-1808.

[33] S.D. Antolovich, R.W. Armstrong, Plastic strain localization in metals: origins and consequences, Prog. Mater. Sci. 59 (2014) 1-160.

[34] ASM Handbook. Volume 8: Mechanical Testing and Evaluation, ASM International, Park, USA, 2000 Member Customer Serv. Cent. Mater.

[35] A. Chatterjee, D. Chakrabarti, A. Moitra, R. Mitra, A. Bhaduri, Effect of deformation temperature on the ductile-brittle transition behavior of a modified $9 \mathrm{Cr}-1 \mathrm{Mo}$ steel, Mater. Sci. Eng. A 630 (2015) 58-70.

[36] V. Dudko, A. Fedoseeva, R. Kaibyshev, Ductile-brittle transition in a 9\% Cr heatresistant steel, Mater. Sci. Eng. A 682 (2017) 73-84.

[37] N. Dudova, R. Mishnev, R. Kaibyshev, Effect of tempering on microstructure and mechanical properties of boron containing 10\% Cr steel, ISIJ Int. 51 (2011) 1912-1918.

[38] M.V. Odnobokova, A.Y. Kipelova, A.N. Belyakov, R.O. Kaibyshev, Mechanical behavior and brittle-ductile transition of high-chromium martensitic steel, Phys. Met. Metallogr. 117 (2016) 390-398.

[39] R. Chaouadi, A. Fabry, On the utilization of the instrumented Charpy impact test for characterizing the flow and fracture behavior of reactor pressure vessel steels, Eur. Struct. Integr. Soc. 30 (2002) 103-117.

[40] ASM Handbook, Fractography, ASM International, 1987.

[41] M. Jafari, Y. Kimura, K. Tsuzaki, Enhanced upper shelf energy by ultrafine elongated grain structures in $1100 \mathrm{MPa}$ high strength steel, Mater. Sci. Eng. A 532 (2012) 420-429.

[42] Y. Kimura, T. Inoue, Influence of warm tempforming on microstructure and mechanical properties in an ultrahigh-strength medium-carbon low-alloy steel, Metall. Mater. Trans. A 44 (2013) 560-576.

[43] S700MC High-strength steels for cold-forming, thermomechanically-rolled, Salzgitter Flachstahl GmbH. 〈https://www.salzgitter-flachstahl.de/fileadmin/ mediadb/szfg/informationsmaterial/produktinformationen/warmgewalzte produkte/eng/S700MC.pdf), 2011. 